\title{
Wer trägt die Fahrtkosten bei Hausbesuchen?
}

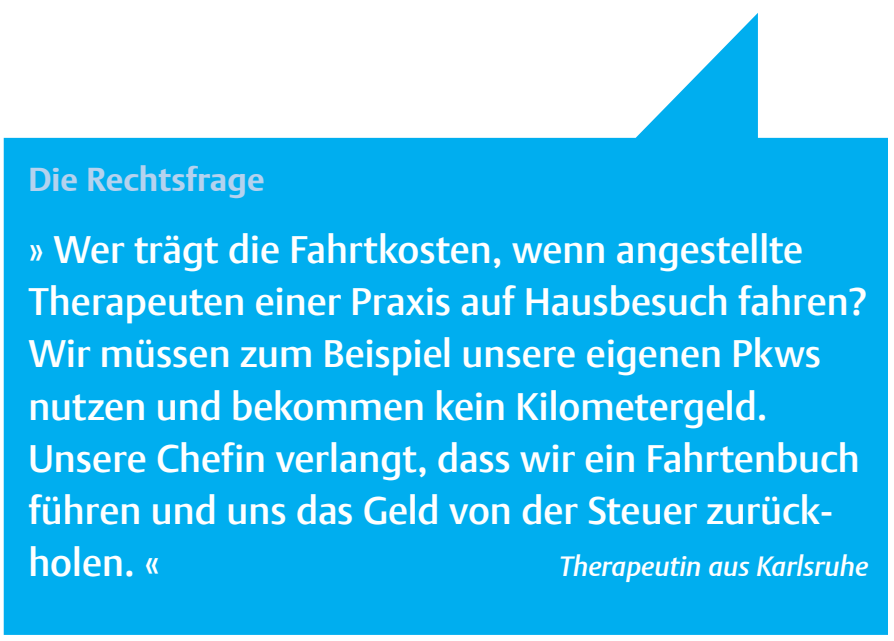

\section{Expertenantwort}

Um Antworten auf die Fragen zu finden, ob Fahrzeit Arbeitszeit ist und wer die Kosten dafür übernimmt, lohnt sich ein Blick in den Arbeitsvertrag. Ist dort oder im Rahmen einer mündlichen Zusatzvereinbarung eine Kostenübernahme durch den Arbeitgeber geregelt? Wenn ja, dann sind die Fragen beantwortet. Ebenso, wenn der Arbeitgeber ein Fahrzeug zur Verfügung stellt (Dienst-Pkw oder Dienst-Fahrrad). Selbstverständlich muss das Fahrzeug für den Mitarbeiter tauglich, verkehrstüchtig und sicher sein. Die Fahrzeit ist in der Regel Arbeitszeit. Ist der Mitarbeiter verpflichtet, seinen eigenen Pkw zu nutzen, sollte man eine Kilometerpauschale vereinbaren. Üblicherweise entspricht sie der steuerlich anerkannten Kilometerpauschale (derzeit 0,30 Euro).

Ohne Pauschale hat der Arbeitnehmer gegenüber dem Arbeitgeber einen Anspruch auf Erstattung der ihm tatsächlich entstandenen Kosten. Zu diesem Aufwendungsersatzanspruch gehören die Kraftstoffkosten. Kosten für Versicherung und Abnutzung muss der Arbeitgeber nur dann anteilig erstatten, wenn dies ausdrücklich vereinbart wurde. Der Aufwendungsersatzanspruch umfasst außerdem Schäden am Auto, sofern diese nicht auf ein allgemeines Lebensrisiko zurückzuführen sind. Dazu gehören zum Beispiel Schäden auf dem Weg zur Arbeit oder wenn das Fahrzeug nur zur persönlichen Erleichterung genutzt wird.

Erleidet der Mitarbeiter während einer dienstlichen Fahrt eine Panne oder einen Unfall oder wird das Fahrzeug beim Parken zwischen zwei Dienstfahrten von nicht zu ermittelnden Dritten beschädigt, gehören die Reparaturkosten zu den vom Arbeitgeber zu erstattenden Aufwendungen. Gleiches gilt unter Umständen für die Rückstufung in der Haftpflichtversicherung. Während der Anspruch des Mitarbeiters auf Erstattung der anteiligen Kraftstoffkosten für den „sparsamen “ Arbeitgeber zuerst überschaubar ist, können diese möglichen weiteren Kosten teuer für ihn werden. Vermeiden kann der Arbeitgeber das Risiko, indem er eine Kilometerpauschale zahlt, die auch bestimmte Aufwendungen des Mitarbeiters umfasst. Erreicht die Pauschale den steuerlich anerkannten Satz, sind damit alle laufenden Kos- ten des Fahrzeugs einschließlich Versicherungen und Reparaturen abgegolten. Die Kosten sind also für den Arbeitgeber planbar.

Entscheidet sich der Arbeitgeber gegen eine Pauschale, kann der Mitarbeiter die ihm bei Dienstfahrten entstandenen Aufwendungen abzüglich der Erstattung vom Arbeitgeber, im Rahmen seiner Steuererklärung geltend machen. Hier reduziert sich aber nur die zu zahlende Steuer, eine richtige Kostenerstattung gibt es nicht.

Gegenüber dem Finanzamt sind dienstliche Fahrten nachzuweisen. Die Führung eines Fahrtenbuchs ist allerdings sehr fehleranfällig, sodass ich empfehle, hierzu einen Steuerberater zu befragen. Karsten Bossow

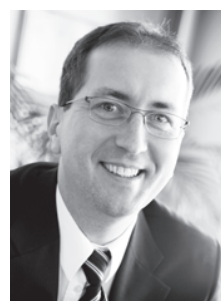

Karsten Bossow ist seit 1999 Rechtsanwalt. Seit 2003 ist er Fachanwalt für Arbeitsrecht und seit 2010 für Medizinrecht. 